Original Research Paper

\title{
Assessment of the Role of Oil and Gas Production Complex in Anthropogenic Changes in Vegetation in Mangystau Region
}

\author{
Lyudmila Pavlichenko, Espolayeva Aikerim, Aliya Aktymbayeva and Iztayeva Aziza \\ Scientific-Research Institute of Ecological Problems, Al-Farabi Kazakh National University, Kazakhstan
}

\author{
Article history \\ Received: 24-02-2016 \\ Revised: 20-03-2017 \\ Accepted: 02-05-2017 \\ Corresponding Author: \\ Aliya Aktymbayeva \\ Scientific-Research Institute of \\ Ecological Problems, Al-Farabi \\ Kazakh National University, \\ Kazakhstan \\ Email: assipova.zhanna@gmail.com
}

\begin{abstract}
The article includes the detailed description of a simplified method of solving the integrated environmental assessment inverse problem. The method was developed by the authors on the basis of using ready map of expert specific environmental assessment of anthropogenic transformation of vegetation in Mangistau region. The first part of the methodology is aimed on obtaining concrete actual evidence which is adapted for the use in objective functions and justification of sufficient objectivity of objective functions. The second part is based on comparison of areas with different levels of anthropogenic impact on vegetation in the whole Mangistau region of the Republic of Kazakhstan and same levels for areas with Oil and Gas Production Complex (OGPC) in the objective functions, in which the loads on the levels of transformation take into account the need for phytomelioration measures. Use of Arc-GIS components has greatly simplified the task, because after conducting digitizing procedure of each contour, vector shape files have been obtained, which areal values are displayed automatically in outlining of each contour. The results of selected field researches were conducted in 2015 serve as independent verification of the objectivity of the obtained results of high level of anthropogenic transformation of vegetation and showed almost complete replacement of eatable plant species by weeds in location of oil well field Zhetybai compared to the state of vegetation outside the sanitary protection zone of the deposit.
\end{abstract}

Keywords: Mangistau Region, Oil and Gas Production, Level of Anthropogenic Transformation of Vegetation, Geoinformation System, Objective Function

\section{Introduction}

Mangistau area - is an archaeological reserve, open air museum, where 11 thousand historical monuments are under State protection. The administrative center of Mangistau region is Aktau city, which grew up in the desert as a result of discovery on a peninsula in the 1950 s of the richest deposits of uranium and rare earth elements, as well as oil and gas. Later new cities and towns appeared on the map: Zhanaozen, Zhetybai, Kalamkas and Karazhanbas (Mangistau regional government. (n.d.)).

A strong degree of anthropogenic disturbance in the Republic of Kazakhstan is related to the extensive development of industries because oil and gas industry - is one of the most ecologically dangerous sectors of economy (DNRECMR, 2014)). Specific climatic conditions of
Mangistau region, which cause the development of deflationary and wasteland processes, formation of scarce soil-plant surface with low capacity to mitigate the effects of anthropogenic influences, determine high environmental safety requirements (Ecology of oil extraction complex. (n.d.); Moskovchenko, 1998).

Research in the field of evaluation of environmental hazards of various raw material sectors of economy showed that ecological environmental assessment on the basis of Maximum Permitted Concentration (MPC) of certain harmful elements in various environments is not acceptable for a number of elements, primarily heavy metals (Abalakov, 2010). In evaluating the effect of harmful substances on ecosystems, not their initial concentration in any environment can be a determining factor but transfer, accumulation and transformation in critical ecosystem links, which result in other 
concentrations and secondary products with other toxic properties. Thus, the environmental standards of permissible impacts on living component of biosphere should be determined by character and patterns of distribution, accumulation, destruction and transformation of pollutants in ecosystems, their transition from one medium to another at local, regional and global levels (Alekseenko, 2000; Milkov, 1990).

These standards cannot be the same for all types of ecosystems, therefore there is a need in developing integrated environmental assessments, taking into account the role of different factors affecting the ecosystem in view of their resistance level (Avessalamova, 1992). Ecological assessments are called integrated due to the necessity of taking into account a large number of measured parameters which are used to assess the impact on specific components of environment (they are called specific environmental assessments), or on all components (they are called integral or total environmental assessments) (Pentl, 1979).

Due to great complexity, the solution of the problem of integrated ecological assessment is traditionally based on expert methods, that has main disadvantage like subjectivism, therefore in accordance with the decisions of numerous international environmental conventions, with the assistance of the International Development Bank, a number of recommendations on the areas' surveys and their comprehensive assessment have been developed (Guidelines for preparation of reports on environmental assessment (n.d)). Currently, economic issues arising from strict standards of compliance with environmental safety regulations have resulted in the need of account of economic component in environmental studies, taking into account the dynamic changes in specific ecosystem components (Araujo and Luoto, 2007).

As a result of joining of the former Soviet republics virtually to all environmental conventions, from the last quarter of the XX century by present period they are rapidly developing methods of conducting integrated environmental assessment, developing guidelines for assessing basic processes that form the level of environmental tension (Bevers and Hof, 1999; Boumans and Costanza, 2002; Costanza et al., 1993; Cousins et al., 2003). In Kazakhstan, as a whole, including the authors of this paper, methods of integrated environmental assessment have been also developed for several years (Pavlichenko et al., 2002; $2010 ; 2012$ ), which are based on estimation objective function (Pentl, 1979).

Integrated environmental assessments enable to differentiate the areas by the level of human impact disturbance, but they are not able to outline the role of not only specific sources of pollution, but also the entire regional industrial complexes. This can be explained by the fact that technical means of monitoring that serve as a source of actual data on environmental status, reflect the influence of many sources of human impact on the state of air, soils, vegetation, terrain, surface and groundwater through a series of measured values.

However, the independent assessment of contribution of specific sources to these integrated or specific environmental assessments is also needed for objective implementation of "the polluter pays" principle. So, practical issues of economic assurance of environmental measures require solution of a new theoretical problem which is closely related to the problem of objectification of integrated environmental assessments, so-called "reverse" objective of integrated environmental assessment. The solution to this problem is the aim of the grant project performed by the authors, which is funded by the Ministry of Education and Science of the Republic of Kazakhstan №0589/GF-4 "Development of the method of objectification of expert assessments of contribution of specific sources of pollution to general environmental situation of the territory". The work plan of this project suggests two ways of constructing the algorithm of solving the inverse problem-through the use of ready expert specific environmental assessments of human impact modifications of terrain, vegetation, soils and groundwater from the Atlas of Mangystau region (Medeu, 2011) and through the use of multivariate statistical models.

At the initial research stage of the project the first way of constructing algorithm of solving inverse problem is implemented - the problems of constructing specific objective functions and calculation of their numerical values for each component of natural environment are consistently solved. The stage should be completed by construction of integrated objective function as a tool of management decisions (objectification of the principle "polluter pays") as a whole in the oil and gas production sector in Mangistau region. Brief summary of the first author's result at this stage - is the solution of the inverse problem of determining the role of oil and gas production complex in human impact disturbance of the terrain based on the use of ready expert specific environmental assessment is described in the study (Pavlichenko et al., 2015).

The aim of this work is to describe the methodologies of objectification of specific objective functions and solution of inverse problem of integrated environmental assessment for quantitative determination of contribution of oil and gas production complex-OGPC to anthropologic transformation of vegetation in Mangistau region based on the use of ready expert specific environmental assessment.

\section{Material and Research Methods}

Since each research method is focused on specific character of initial materials, let us first consider the methods of development and attempts of objectification of integrated environmental assessment, analysis of 
successful use and development, which involved Kazakhstani scientists (Pavlichenko, 2008; Pavlichenko and Nysanbayeva, 2001; Pavlichenko and Kurbatova, 2006; Pavlichenko et al., 2002; 2010; 2012; 2015)

Currently the "integrated environmental assessment" concept is multi-valued, since the object of assessment includes specific objects, their complex, as well as a complex of object description parameters. The variety of integrated environmental assessment types is also determined by different objectives, techniques, volume of estimated components, character of parameters and objects. In developing integrated environmental assessment in the absence of standardized methods, the developers often independently introduce concepts of integrated assessment, the extent of its information content, develop methods of obtaining comprehensive evaluation, interrelations of parameters and their classification. Account of spatial distribution of parameter transfers a comprehensive environmental assessment to geoecological, formulating new criteria for environmental zoning of human impact on the research area taking into account the possibility of terrain selfremediation (Pavlichenko, 2008).

Classical assessment of natural system condition is performed based on comparison with standard systems and is possible in measurement of the degree of excess of quantitative values of environmental factors. Various standards often serve as a model of optimal condition of natural environment. In assessing the impact of environmental factors on environmental condition, the interaction between influencing factors and response of geosystems to this impact should be taken into account (Avessalamova, 1992; Gmoshinsky, 1977; Mukhina, 1973). Here occurs the issue of fixing threshold reaction value of biotic component, when the impact of environmental factor becomes negative. The complexity of solving the latter problem, as noted by Mukhina (1973), is determined by the fact that in conducting specific evaluation works, the experimental set of index values is often more narrow and does not reach critical values and therefore the researcher faces only unidirectional subject indexes changes and the object in development of specific assessment scales (either in ascending or descending part of tolerance curve).

Most often, the standards of maximum permissible emissions and maximum permissible discharges serve as threshold values, which excess leads to violation of Maximum Permissible Concentration (MPC) of relevant pollutants in air, soil, groundwater and surface water (Chepurnykh and Novoselov, 1995).

Existence of optimum range of values for each influencing factor is a natural factor and deviations will become negative both upward and downward from optimum conditions, since there is an ecological niche of optimal environmental conditions for every living organism. Therefore one of the key points in assessment of the impact is the development of specific assessment scales and in the process of it's development, it is necessary to align two sets of indicators, one of which characterizes the state of environmental factor and other - the state of geoecosystem biotic component. Evaluation logic is presented in (Avessalamova, 1992) and is as follows: Study of factor and its indicators $\rightarrow$ data collection on environmental interactions and identification of biotic component responses $\rightarrow$ selection of criteria and development of specific assessment scales $\rightarrow$ assessment of impact factor and determining of spatial variation, which can be presented on specific maps.

Thus, the problem of assessing the impact of specific environmental factor is aimed to chose a set of parameters, which most objectively characterize this factor and develop assessment scales. In comprehensive assessment it is necessary to take into account not only the intensity of impact of each environmental factor, but also its role (importance) in formation of favorable or adverse conditions of biosystem existence. Since the significance of each environmental factor and direction (plus or minus) of its impact is determined by the purpose of integrated assessments (favorable or unfavorable factor from the viewpoint of the object under the impact), Pentl (1979) proposed to call the assessment function as target. He proposes the simplest type of such complex assessment as a linear multiple regression equation:

$C E A=\Sigma$ air. $=a_{1} \oplus f_{1}+a_{2} \oplus f_{2}+\ldots+a_{n} \oplus f_{n}$

Where:

$C E A=$ Estimated value of complex environmental assessment

$f_{i}=$ Value of specific environmental factor $(i=1,2$, $\ldots, n)$ at observation point

$a_{i}=$ Weight coefficient taking into account the direction (positive or negative) and the importance (weight) of this factor in formation of total impact level

For convenience in use of this function weight coefficients sometimes are normalized by the sum of their absolute values by 100,10 and 1 . In this case, the average load on parameter is $100 / \mathrm{n}, 10 / \mathrm{n}$ or $1 / \mathrm{n}$. Increased pressure above one of these values indicates the increased role of factors that describe relevant parameter in formation of general human impact situation.

In this formulation, objective function is understood not in classical mathematical sense (where it is understood as a criterion for comparing alternatives using different optimization methods), but as function that implements the purpose of assessment. Formal similarity with mathematical sense is also observed and here - optimization procedure lies in a simple enumeration of $a_{i}$ 
coefficients significance (almost always expert assessments) in compliance with their justification.

In conducting impact assessments we often deal with lack of quantitative data on impact of environmental factors, in this case, we use methods of expert assessment, which summarize the accumulated research experience on the impact of various environmental factors. But this fact of impossible use of measuring "ruler" serves as a basis of generally accepted view on subjective feature of expert assessments.

As the above Equation 1 does not take into account the effects of interaction of impact factors, accuracy of assessment will increase with the increase of their number. The work (Gmoshinsky, 1977), devoted to popular presentation of ideas of engineering ecology which considers ecology from the general system theory point of view and information quantitative theory (Jeffers, 1981; Peregudov and Tarasenko, 1989), presents a very simple formula for calculation of sufficient number of parameters $n$ (environmental factors in the above equation) at the desired assessment accuracy:

$\Delta=\frac{1}{l^{n}}$

where, $l$ - is level of quantization of assessment scales used in assessment of environmental factors ( number of divisions of assessment scale).

Formula (2) shows that even at the most rough assessment scale with level of quantization 2 (i.e., for expert assessment on principle "yes" or "no") reasonable accuracy (error does not exceed 4\%) can be achieved at 5 accounted parameters $\left(=1 / 2^{5}=0,03125\right.$, or $\left.3,1 \%\right)$. Thus, large effect on accuracy (i.e., actually on objectivity) of expert grades has the number of analyzed parameters $n$ (exponent of denominator in formula), but not the level of quantization of assessment scales $l$ (number of divisions on our measurement "ruler").

However, in this case also, there are problems of choosing most significant factors and development of specific and integral scales. Selection of the most significant factors is justified by specific geographical, environmental and economic conditions of the evaluated territory, so we will consider the following basic phase of constructing objective function-development of specific and integral scales.

In manuals which have been developed by various foreign organizations, indicators of certain various effects play the role of integrated environmental assessment indicators (Assessment of the impact of economy on the environment, 1985). The term "indicator" corresponds to the term "criterion" in the literature of the post-Soviet space and should reflect the problem in a broader sense (Sokolov, 1992). For example, the level of heavy metals in soil indicates not only contamination by metals, but usually toxic pollution situation. Indicators also may aggregate specific parts of information, for example, water quality index or index of greenhouse gas emission. There are attempts to construct summarized indicators on the basis of multivariate models, which do folding of information (component and factor analysis, cluster analysis, argument account group method) (Burakov and Pavlichenko, 2001).

The most crucial moment determining the degree of objectivity of integrated environmental assessments, is design of specific rating (assessment) scales. If every parameter from their available set is assessed on a scale constructed on the basis of independent research on its whole possible range of changes, we can speak about the objectivity of integrated assessments, as their scale is determined by the type of objective function (Mukhina, 1973).

Now let's consider the description of initial information, which serves as a basis for obtaining factual data for our constructions and analysis of its objectivity degree by significance of selected impact factors and authenticity from point of view of environmental engineering.

In interconnected system of landscape forming factors, vegetation is one of the major functional ecosystem blocks, one of the most dynamic, responsive to changing conditions and soils, terrain, water and air. According to its state, floristic and cenosis diversity we can judge about the speed and direction of anthropogenic and anthropogenic stimulating processes, dynamics of other ecosystem components (soil, groundwater and surface water, etc.) (Cousins et al., 2003).

The work (Imanbaeva and Sagyndykova, 2009) is devoted to the monitoring of vegetation on the field Karazhanbas in Mangistau region, also highlights high informative role of vegetation which can act as indicator of anthropogenic disturbance of the area. In general, vegetation cover of the peninsula is formed in harsh natural conditions of the northern deserts - dry climate with sharp fluctuations in temperature, high humidity deficit, high levels of soil salinity and is characterized by a uniform spatial structure, scarce flora, low biological diversity level. It is noted that in sites adjacent to technological objects (wells, roads, etc.), vegetation cover has undergone transformation.

Since the first way to solve the "inverse" problem initially assumes availability of complex expert assessments as initial material, evaluation map of anthropogenic modifications of vegetation from the "Atlas of Mangystau region" has been used (Medeu, 2011). This map is shown in Fig. 1.

The map was developed by the Institute of Geography, Ministry of Education and Science of the Republic of Kazakhstan on the basis of expert assessments of materials of research expeditions and interpretation of data on area remote sensing. Legend to the map includes characteristics of location of areas subject to different levels of anthropogenic transformation: 


\section{Undisturbed}

Areas occupy vast areas in the south of the region. These are mainly southern deserts types-tytr and kemore-sagebrush. North-eastern and eastern regions with predominance of complex deserts where grow boyalych, Anabasis salsa and Artemisiaterrae-albae, are practically undisturbed. Sporadically undisturbed areas are found on the Sea coast. These territories are characterized by insignificant level of transformation, or its absence and are presented on the map in green color.

\section{Slightly Disturbed}

Territories are spread over large spaces of the region and are particularly common in mountainous Mangystau. The vegetation cover, which is very valuable, has slightly transformed in recent years due to intensive development of surrounding spaces and exploration work. Weak disturbances of vegetation surface are typical for large spaces on Ustirt (central and northern parts). These areas are characterized by low levels of transformation and are presented on the map in light green color.

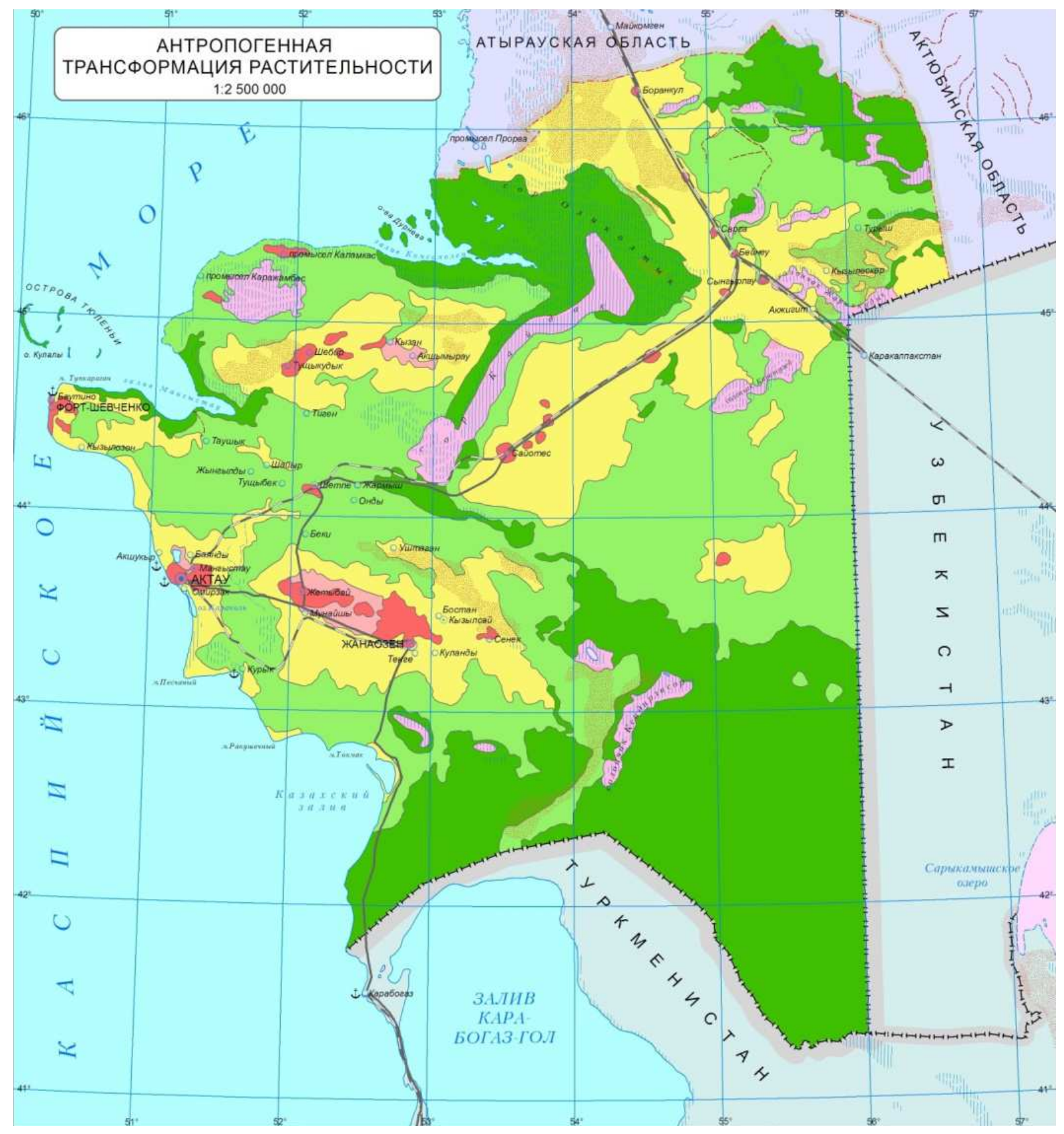

Fig. 1. Map of plant transformation caused by human impact 


\section{Average Disturbed}

Areas are common in areas surrounding major towns and are well observed along the railway route and pipelines in the Caspian depression. Large part of Bozaschy and Tupkaragan peninsulas refer to average disturbed areas. All sand areas of the region can be attributed to average disturbed areas. These areas are characterized by moderate level of transformation and are presented on the map in yellow color.

\section{Strongly Disturbed}

Territories are associated with deserts on soils of light mechanical composition (sandy loam, sand) in central part of Bozaschy peninsula. In addition, large areas of strongly disturbed vegetation surface are observed on Mangystau peninsula, on spaces surrounding oil extraction areas and towns (Zhanaozen, etc.). These areas are characterized by significant level of transformation and are presented on the map in pink color.

\section{Very Strongly Disturbed}

Areas are typical for oil fields and surrounding settlements. These areas are characterized by strong level of transformation and are presented on the map in red color (Medeu, 2011).

Apart from impact factors mentioned in description of areas of various levels of anthropogenic transformation of vegetation, the legend includes photographs of sites which show the expression of anthropogenic transformation of vegetation factors which are the most typical for the area - oil and gas production and overgrazing. Thus, the analysis of the legend gives reason to conclude that there are sufficient numbers of impact factors in outlining of areas with different levels of anthropogenic disturbance. These factors include main types of human activities on the territory: Oil and gas production, exploration works, availability of oil and gas pipelines, residential areas, transport routes, overgrazing (6 factors).

We should particular note that the impact of these factors was evaluated not only according to the inventory of different types of activities (such maps are also represented in the Atlas), but also by classical landscape criteria - change in species composition (by ratio of dominant and weedy species, or even change of dominant species) as well as plant vitality. This conclusion follows from concurrency of contours on several maps presented in Atlas (Medeu, 2011) which reflect diverse vegetation types in Mangistau region. Even surface review shows that map of anthropogenic transformation is based on a series of expert conclusions of a number of other maps. Among them is a map of vegetation on which 32 complex desert and semi-desert plant communities have been considered within 82 ecosystem types; map of botanical-geographical zoning (10 counties with 35 districts) and inventory map of anthropogenic impact sources.

So, 5 basic parameters (5 levels of anthropogenic transformation of vegetation outlined in 5 color shades) of expert map actually contain generalization of information at least of 32 complexes of plant communities and at least 6 factors of anthropogenic impact on vegetation. Therefore we can state that check of the map of anthropogenic transformation of plants from position of selecting main factors of transformation of vegetation, as well as the number of parameters taken into account showed full compliance with requirements of objectivity of the importance of selected impact factors and credibility from the standpoint of environmental engineering (Avessalamova, 1992).

In addition to description of the main types of human activities in the territory, which act as impact factors in assessment of the degree of anthropogenic transformation of vegetation, the legend to the map contains very important information for construction of target function. The legend states that levels of vegetation transformation are combined not only from the standpoint of completeness and quantitative correlation of a set of dominant and accompanying species, presence of weed species, but also by the degree of preservation of their vitality, i.e., their ability to self restoration. Thus, level of transformation of vegetation is inversely proportional to the ability of self restoration and necessary costs of environmental restoration - are proportional to the disturbance degree. This fact also provides economic basis for objectification of weighting factors which are taken into account in target function factors.

So, for solution of the inverse specific (in this case only vegetation is considered) objectives of integrated environmental assessment there are all reasons to consider the accuracy of initial data sufficient to assess the role of oil and gas complex of Mangistau region in anthropogenic transformation of vegetation.

For account of the impact of transformation of vegetation in OGPC another map from the Atlas (Medeu, 2011) - "Oil and Gas Production Complex" was used, which reflects location of hydrocarbon fields developed by OGPC and the legend provides their titles. This map is an inventory, therefore its objectiveness doesn't require verification. The required accuracy is ensured by concurrence of scales of assessment and inventory maps.

Let's now turn to presentation of methodology of assessment of the role of OGPC in vegetation transformation.

The main idea of solving the inverse objective of integrated environmental assessment is to propose the method of comparing areas of different levels of 
human impact on vegetation in the whole Mangistau region of the Republic of Kazakhstan and in areas with OGPC, as first simplified approach. The method is implemented by means of target functions, taking into account the levels of human impact on vegetation of all sources of impact, first across the region and then in OGPC areas.

Use of Arc-GIS software components greatly simplifies the task because transfer of assessment map into vector format provided determination of the areas of spread of five levels of human impact on vegetation in the whole region. Overlay of the layer with OGPC contours on this map made it possible to determine the areas of dissemination of five levels of human impact on vegetation inside OGPC contours.

Determining of the areas of anthropogenic transformation of vegetation on the original assessment map was based on specific data of maps of the Atlas of Mangystau region, which were subsequently digitized in ArcMap component by overlaying. Through digitization process, we get vector shape files, which areal values will be automatically displayed in outlining of each contour (Fig. 2).
Figure 3-5 demonstrate methodology of getting initial data for solving the inverse problem of environmental assessment. For clarity Fig. 3 shows a fragment of the map of anthropogenic transformation of vegetation on a larger scale (fragment of Fig. 1). Figure 4 shows the icons of oil and gas production (for the same fragment - "Oil and gas production complex" is taken from inventory map (Medeu, 2011)) and Fig. 5 - a fragment of the resulting map is obtained by combining Fig. 3 and 4 (contours of hydrocarbon deposits have been delineated in advance in big scale from GoogleMap and then applied to assessment map scale).

Spot data of oil and gas fields from inventory map were placed in the lower layer for getting areas with OGPC and buffer zones of each deposit from the GoogleMap in the upper polygon layer, given in scale of assessment and inventory maps and their combination provided getting of OGPC contours. The problem of determining contours of OGPC impact within each color contour of assessment map was solved by means of activation of OGPC impact contours layers and assessment map (Fig. 5)

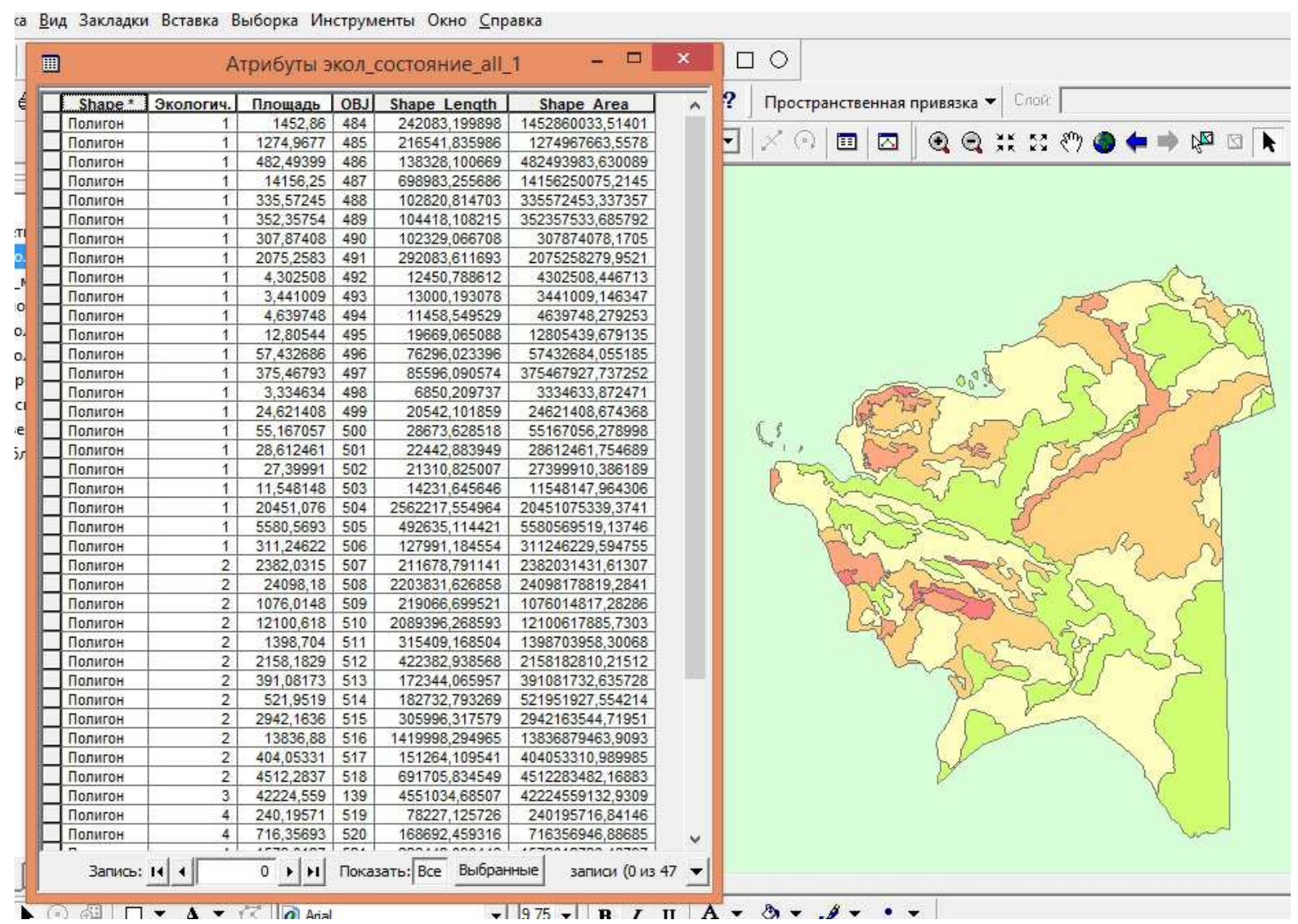

Fig. 2. Demonstration of procedure of obtaining a real values of specific contours by means of vector shape files 


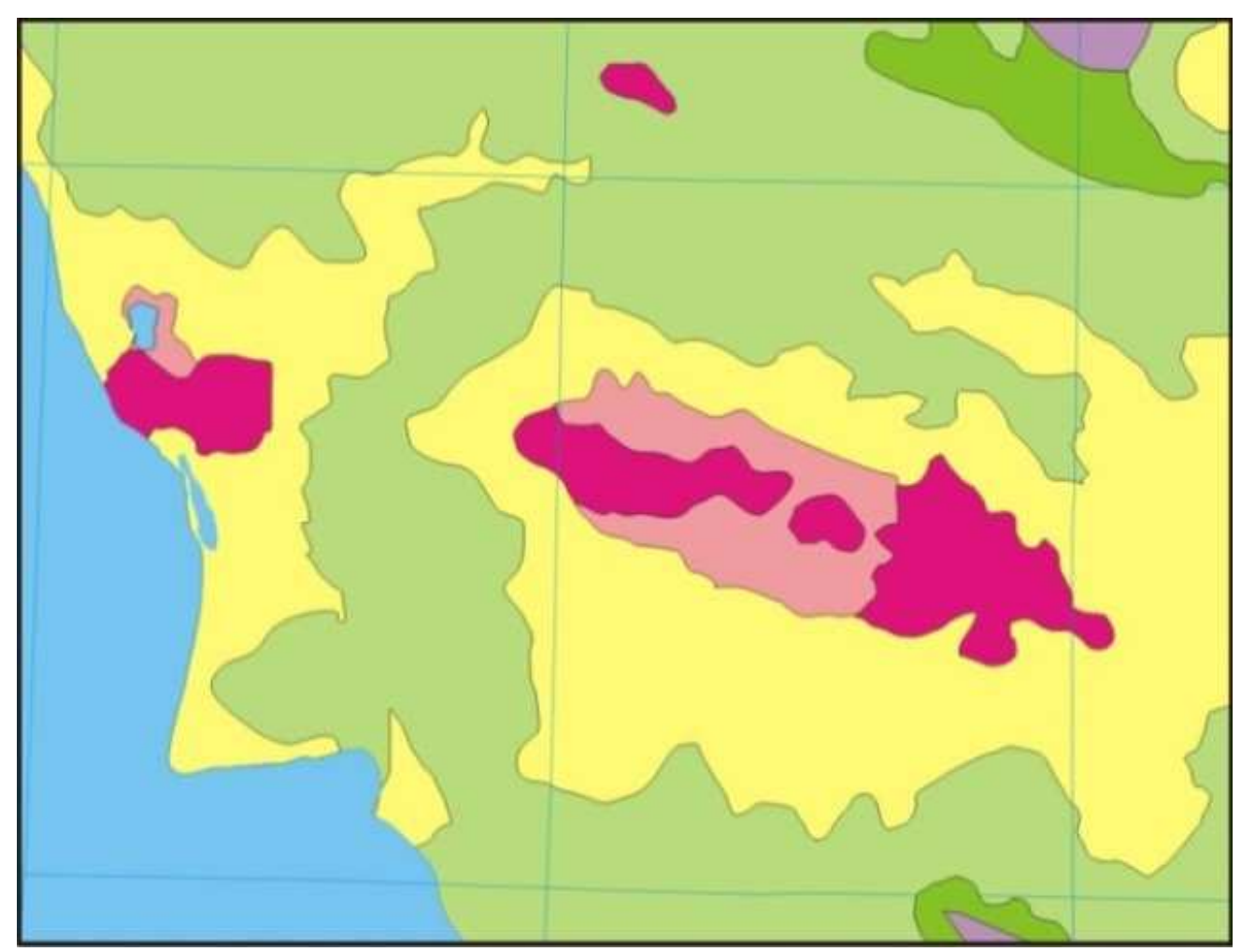

Fig. 3. Fragment of map of anthropogenic vegetation transformation

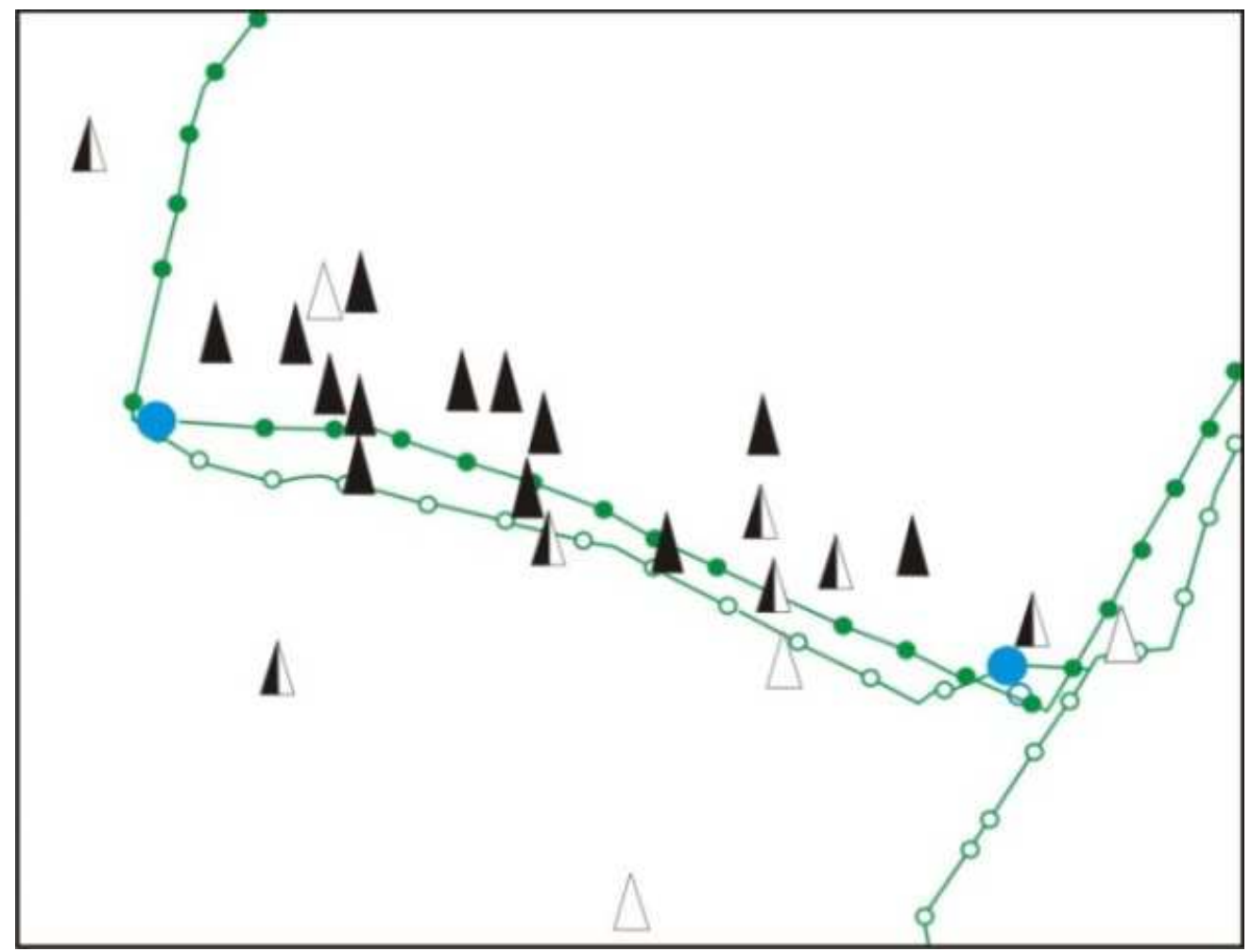

Fig. 4. Signs of oil and gas production (for fragment on Fig. 2) 


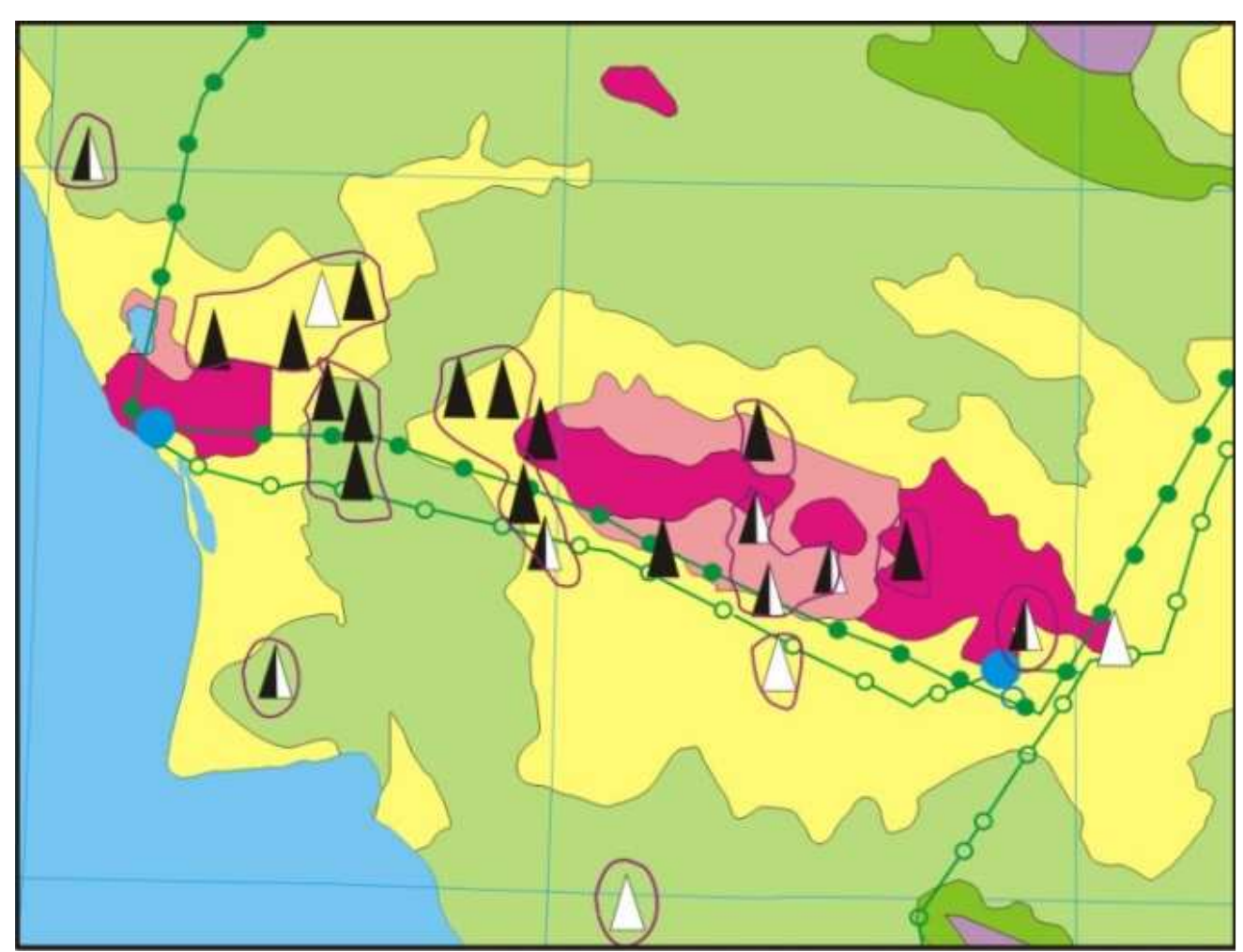

Fig. 5. Scheme of outlining contours of hydrocarbon deposits in zones of various degree of anthropogenic transformation of vegetation

Estimation procedures are performed with the help of target functions, compiled for the whole region in general and for part of regional territory, on which areas of hydrocarbon deposits were delineated. In the first case, for obtaining total estimates, the areas of all sites with the same color have been summed, i.e., areas of all sections with the same level of anthropogenic transformation of vegetation on the territory of the region as a whole have been summed (i.e., taking into account all 6 factors of anthropogenic transformation of vegetation).

As can be seen from Fig. 4, the icons indicating the spread of OGPC are found in all five color zones, therefore in the second case the areas with the same color have been also summed in the whole region, but only inside the contours of hydrocarbon deposits.

The next step in computation procedure is justification of the type of target functions. Since we are using ready assessment map as an initial factual material, which objectivity and accuracy of expert assessments are of no doubt, the objective of justification of assessment parameters becomes elementary - there are 5 colors on the map, each of which corresponds to a certain level of vegetation transformation. Thus, the number of $f_{i}$ parameters in the objective function, which should describe anthropogenic transformation at all levels is assumed to be 5 , i.e., the number of transformation levels outlined on the assessment map.
Now we have to justify the characteristics of weighting factor $a_{i}$ which takes into account the direction (positive or negative) and the importance (weight) of corresponding factor in formation of total impact level. Since the purpose of assessment is the role of OGPC in anthropogenic transformation of vegetation, we will indicate the direction of transformation by positive mark (negative changes).

In case of compliance of all five levels of vegetation transformation, we will determine weight loads of each parameter of the objective function in traditional ten-point scale of expert estimates. In case of linear scale each of 5 levels will have 2 points and increase of transformation level will correspond to the increase of point grade.

This statement is justified from the standpoint of complexity and cost of environmental protection measures, in particular measures on remediation of the territory. As noted above, the legend to the map in Fig. 1 describes the possibility of rehabilitation of vegetation cover in areas with varying degrees of transformation. Weak disturbed plant communities are able to restore in case of limited impacts. Strong disturbed plant communities are able to restore at complete stop of the effects. Very strongly disturbed plant communities are not able to restore without phytomelioration measures.

As the cost of activities is growing in proportion to the degree of anthropogenic disturbance, we will conduct 
specific environmental assessment of the input to each zone in accordance with a weight factor which is proportional to the level of transformation in point grading scale. In this case, the lower and upper limits of 5 levels (parameters of objective function) are the points:

- For insignificant level or lack of transformation (green color on the map) $-0 \div 2$

- For low-level transformation (light green color on the map) $-2 \div 4$

- For moderate levels of transformation (in yellow on the map) $-4 \div 6$

- For significant transformation (pink on the map) $-6 \div 8$

- For strong transformation level (red on the map) $8 \div 10$ points

Taking average values between limits of class values for calculation of average weight value of contribution of oil and gas production complex to anthropogenic transformation of vegetation, we obtain the following form of specific objective function for overall assessment of plant transformation of the region (STFvegReg):

$$
\text { STFvegReg }=f_{1}+3 \oplus f_{2}+5 \oplus f_{3}+7 \oplus f_{4}+9 \oplus f_{5}
$$

where, $f_{i^{-}}$is value of total area of polygons with certain level of anthropogenic transformation of vegetation in the region in general.

Special attention should be paid to this issue. Since not variables but concrete values are used as $f_{i}$ - the sums of all contours of one color ( 5 samples from Table of shape files attributes), the result of solution (3) will be only 1 result the number which characterizes average anthropogenic transformation of vegetation in the whole region.

To solve the inverse problem of integrated environmental assessment by comparing areas of different levels of human impact on vegetation in the whole Mangistau region of the Republic of Kazakhstan and areas with OGPC, we need to build assessment function for OGPC areas in the same way. Since these areas are determined by the same assessment map, the difference of specific objective function from the objective function for the overall vegetation transformation in the region for zones of location of deposits $\left(\mathrm{SOF}_{\text {vegOGPC }}\right.$ ) will be only in values $f_{O G P C i}$. Now these are areas of color zones only within OGPC contours) and weight loads remain the same as in the Equation 3:

$$
\begin{aligned}
& S O F_{\text {veg } O G P}=f_{O G P C 1}+3 \oplus f_{O G P C 2} \\
& +5 \oplus f_{O G P C 3}+7 \oplus f_{O G P C 4}+9 \oplus f_{O G P C 5}
\end{aligned}
$$

Like in case (3) in Equation 4 not variables but specific values will be obtained - the sum of all contours of one color ( 5 samples from Table of shape files attributes for contours with OGPC) as a result of solution
(4) only 1 result will be obtained- the number that describes the average human impact on plant transformation but now not across the whole region, but only in the part of OGPC location.

In Equation 3 and 4 weight loads which are measured in points are multiplied by area value. Thus, as a result of calculation of objective functions for the entire territory of the region and OGPC zones, total point areas are obtained.

The role of OGPC in transformation of vegetation of the region as a whole is determined by dividing the value $\mathrm{SOF}_{\text {vegOGPC }}$ by value $\mathrm{SOF}_{\text {vegReg }}$ at all levels of human impact on transformation. The value which resulted in unit fractions is transferred into percentage and represents an additional (as in $\mathrm{SOF}_{\text {vegReg }}$ the cumulative effect of all 6 major factors is reflected through changes in species composition and ability to self restoration) OGPC contribution to vegetation transformation.

\section{Results and Discussion}

The aim of this work is to get methodological results (by objectification of specific objective functions and solution of inverse problem of integrated environmental assessment) and quantitative result-determination of OGPC contribution to human impact on vegetation transformation in Mangistau region on the basis of use of ready expert specific environmental assessment.

Methodical results follow from the previous section and we give more concentrated formulation.

\section{Results of Objectification of Specific Objective Functions}

On the basis of the review of a large amount of literature, performed in the previous section, the content of the concept of the objective function in accordance with R. Pentle, can be presented as follows. This is function of complex environmental assessment in form of multiple linear regression equation indicating the purpose of assessment and determination of a set of the most important parameters (impact factors characteristics) in which record the value and load sign determine the role and direction of influence of parameter on purpose of assessment:

$O F_{C E A}=a_{1} \oplus f_{1}+a_{2} \oplus f_{2}+\ldots+a_{n} \oplus f_{n}$

Where:

$O F_{C E A}=$ A calculated value of objective function for complex environmental assessment

$f_{i}=$ Value of a specific environmental factor $(i=$ $1,2, \ldots, n)$ at observation point

$a_{i} \quad=$ Weight factor taking into account the direction (positive or negative with respect to the target) and the importance (weight) of this factor in formation of total impact level 
Objectification of objective function previously included justification of the choice of the most significant factors taking into account specific geographical, environmental and economic conditions of evaluated area and completeness of assessment scales range and the latter issue was considered as the most difficult issue.

Methods of environmental engineering from the standpoint of general theory of systems and quantitative information made it possible to link the completeness of the range of assessment scales (quantization levels in terms of information theory) with a number of parameters (effect of intra-system relations) by calculating minimal number of parameters at the desired level of accuracy of description by simple formula (2). Thus, in the problem of objectification the pure expert approaches were used only in justifying the choice of the most important factors. We can consider that this part of the stated purpose of work has been achieved.

\section{The results on the methodology of solution of inverse problem of integrated environmental assessment on the basis of use of ready map of expert specific environmental assessment of human impact on vegetation transformation in Mangistau region.}

Methodology of solution consists of two parts methodology of obtaining specific factual data in a form adapted for use in objective functions which implement a simplified method of solving the inverse problem and justification of sufficient objective functions. The first part of methodology is based on justification of objectivity and sufficiency of materials used in developing resulting map of human impact on vegetation modification, which is also sufficient to form a kind of objective functions of exact parameters of resulting map using new techniques of objectification of specific objective functions.

The second part of methodology is based on comparison of areas of different levels of human impact on vegetation in the whole Mangistau region of the Republic of Kazakhstan and the same levels for areas with OGPC in objective function represented in Equation 3 and 4 in which the loads on transformation levels take into account the degree of necessity of phytomelioration measures.

Specific data of maps of the Atlas of Mangystau region served as a basis for determining the areas on the initial assessment map of human impact on vegetation transformation, which were subsequently digitized in ArcMap component by means of overlaying. Conducting digitizing procedure provided obtaining of vector shape files, which areal values are automatically displayed in outlining of each contour.
For getting areas with OGPC, spot data from oil and gas fields from inventory maps were placed in the lower layer and in the upper polygon layer - buffer zones of each deposit from GoogleMap, given in the scale of assessment and inventory of maps, their combination provided impact contours of OGPC. The problem of determining the impact contours of OGPC within each color contour of assessment map was solved by activation of OGPC impact contour layers and assessment map.

The results of determination of OGPC
contribution to the anthropogenic
transformation of vegetation in Mangistau
region based on the use of ready-made expert
specific environmental assessment

In accordance with methodology of simplified solution of the inverse problem of integrated assessment, we need to determine total areas of zones with the same color, based on the procedures of obtaining area values of specific contours, by means of vector shape files. According to the map of human caused modification of vegetation of Mangistau region, the sums of contour areas of each five colors have been obtained which reflect levels of anthropogenic transformation of vegetation throughout the whole region (the first row of Table 1). Based on resulting map of combination of inventory and assessment maps the sums of the areas within OGPC contours have been obtained (second line in Table 1).

In this case, Equation 6 and 7 are converted to the form (8) and (9), respectively:

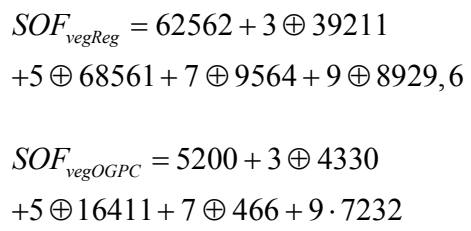

The third row of Table 1 presents share of area of OGPC contours in zones by levels of transformation, expressed in percentage, which shows the increase of proportion of areas of OGPC contours as the degree of anthropogenic transformation of vegetation grows:

- $8,3 \%$ for green zone (degree of anthropogenic transformation of vegetation is insignificant or absent)

- $11,1 \%$ for light green area (degree of anthropogenic transformation of vegetation is weak)

- $23,9 \%$ for yellow zone (level of anthropogenic transformation of vegetation is moderate)

- $46,7 \%$ for pink zone (degree of anthropogenic transformation of vegetation is significant)

- $81,0 \%$ for red zone (degree of anthropogenic transformation of vegetation is strong) 
Table 1. Assessment of the proportion of area contours OGPC in areas on the field zones

The degree of anthropogenic transformation

\begin{tabular}{llllll} 
& Unconsiderableorno & Weak & Moderate & Considerable & Significant \\
\hline $\begin{array}{l}\text { The total area of the zones on the levels of } \\
\text { transformation in the whole area, } \mathrm{km}^{2}\end{array}$ & 62562 & 39211 & 68561 & 9564 & 8929,6 \\
$\begin{array}{l}\text { The total area of the contours OGPC in areas } \\
\text { and levels of transformation } \mathrm{km}^{2}\end{array}$ & 5200 & 4330 & 16411 & 4466 & 7232 \\
$\begin{array}{l}\text { The proportion of area contours OGPC in areas } \\
\text { and levels of transformation } \%\end{array}$ & 8,3 & 11,1 & 23,9 & 46,7 & 81 \\
\hline
\end{tabular}

Table 2. Calculation of the average OGPC contribution in anthropogenic transformation of vegetation on the territory of Mangistau region

\begin{tabular}{|c|c|c|c|c|c|c|}
\hline The degree of anthropogenic transformation of relief & Unconsiderableorno & Weak & Moderate & Considerable & Significant & $\begin{array}{l}\text { Calculated values } \\
S O F_{\text {vegReg }}\end{array}$ \\
\hline Totalarea $\left(\mathrm{km}^{2} \times\right.$ score $)$ & 62562 & 117633 & 342805 & 66948 & 80366,4 & 670314 \\
\hline Total area of contours OGPC ( score $\left.\times \mathrm{km}^{2}\right)$ & 5200 & 12990 & 82055 & 31262 & 65088 & 19 \\
\hline \multicolumn{6}{|c|}{ The weighted average rating of anthropogenic transformation of vegetation in Mangystau region, points } & 3,55 \\
\hline \multicolumn{6}{|c|}{ The weighted average rating of anthropogenic transformation of vegetation on the territory of Mangistau region with OGPC, points } & 5,22 \\
\hline \multicolumn{6}{|c|}{ Additional contributions OGPC in anthropogenic transformation of vegetation in the Mangistau region, $\%$} & 16,73 \\
\hline
\end{tabular}

In absolute terms, maximum area of territories with OGPC belongs to temperate transformation zone. So, the obtained simple comparison of zones by each color on the whole territory of Mangistau region shows contribution of OGPC only to these specific areas of anthropogenic transformation of vegetation.

Generalized assessment can assure calculation of objective functions (8) and (9), taking into account weight load of each zone-reflection of cost of environmental protection measures (Table 2).

Thus, the main aim of this work - is quantitative determination of contribution of OGPC to the anthropogenic transformation of vegetation of Mangistau region - has been achieved as a specific result of solution of a new theoretical problem in the field of integrated environmental assessments. As a result of solution of the inverse problem of integrated environmental assessment, new kinds of assessments were obtained which facilitate addressing of practical issues of economic support for environmental measures implementing the principle "polluter pays" by quantitative assessment of additional contribution of OGPC to anthropogenic transformation of vegetation in Mangistau region, which is $16.73 \%$ higher than average weighted assessment of all impact factors.

The average weighted assessment of anthropogenic transformation of vegetation on the Mangistau regionterritory with OGPC was 5.22 points on a ten point scale with average weight assessment of anthropogenic transformation of vegetation in Mangystau region as a whole of 3.55 points. Based on the results in Table 1, which show the increase in proportion of areas of OGPC contours with growth of the degree of anthropogenic transformation of vegetation, we can draw a conclusion about the possibility of further growth of anthropogenic transformation of vegetation.

The obtained value shows that impact of OGPC on vegetation is beyond the limits of its concrete territories.
Such situation evidences about the need of controlling the methods of organizing production ecological control, which results usually don't show any increase of standards on emissions.

The results of selected field research conducted by authors show confirmed high degree of anthropogenic transformation of vegetation in zone of location of oil and gas production well in Zhetibay oil and gas deposit compared to the state of vegetation beyond the limits of sanitary-protection zone of the deposit. This transformation has expressed in practically complete shift of eatable plants by weeds.

Analysis of the presence of certain species in composition of selected plant samples showed that close to the oil well $95 \%$ of total mass of plants was Harmala (other names: Burial, adraspan, prairie root, Turkish paint). It is a poisonous weed which grows in pastures and strongly overgrazed pastures in the southern steppes and deserts. Other species in the samples near the well are rare samples.

The picture completely changes for the samples taken outside the sanitary protection zone. In the same species composition, Harmala which was prevailing before, becomes a single representative in a small number of samples, not exceeding the amount of $2 \%$ (Pavlichenko et al., 2016).

\section{Conclusion}

The main aim of this work - is quantitative determination of contribution of OGPC to the anthropogenic transformation of vegetation of Mangistau region - has been achieved as a specific result of solution of new theoretical problem in the field of integrated environmental assessments. As a result of solution of the inverse problem of integrated environmental assessment, new kinds of assessments were obtained, which facilitate addressing of practical 
issues of economic support for environmental measures implementing the principle "polluter pays" by quantitative assessment of additional contribution of OGPC to anthropogenic transformation of vegetation in Mangistau region, which is $16.73 \%$ higher than average weighted assessment of all impact factors.

Methodology of solving the inverse problem of integrated environmental assessment has been developed on the basis of use of ready map of expert specific environmental assessment of anthropogenic transformation of vegetation in Mangistau region. The methodology consists of two parts. The first part methodology of obtaining specific factual data in form which is adapted for use in objective functions which implement a simplified method of solving the inverse problem of objectivity and justification of sufficient objective functions. The second part of the methodology is based on comparison of areas of different levels of human impact on vegetation in the whole Mangistau region of the Republic of Kazakhstan and the same levels for areas with OGPC in the objective functions represented in the Equation 3 and 4 , in which loads on transformation levels take into account the degree of the need for phytomelioration measures.

A valuable result of the work is theoretical result obtained due to the review of literature, which is included in the fact that pure expert approaches in objectification problem have been used only in justifying the choice of the most important factors. Methods of environmental engineering from the standpoint of general theory of systems and quantitative information theory made it possible to link the completeness of range of assessment scales (quantization levels in terms of information theory) with a number of parameters (effect of intra-system links) by calculating the minimum number of parameters at desired level of accuracy of description of system by a simple formula (2).

High degree of anthropogenic transformation of vegetation in oil well site area of oil and gas deposit Zhetybai can serve as independent verification of the objectivity of the results and conclusions, compared with the state of vegetation outside the sanitary protection zone of the deposit, which was revealed by the results of selected field works performed by the authors in 2015 . This transformation has resulted in almost complete replacement of eatable plant species by weeds.

\section{Author's Contributions}

Lyudmila Pavlichenko: Conducting a literary review, scientific consultation, defining, conducting the final analusis on the basis of factor analysis:
- Assessment of the proportion of area contours OGPC in areas on the final zones

- Calculation of the average OGPC cntribution in anthropogenic transformation of vegetation on the territory of the Mangistua region

Determination of the main factors influencing the transformation of vegetation in the region under consideration.

Espolayeva Aikerim: Conducting laboratory expeiments on the analysis of petroleum products in vegetation and conducting a comparison with the standards of species of vegetation. Construction of a scheme for the distribution of the load on vegetation in the study areas:

- Diagram: Demonstration of procedure of obtaining a real values of specific contours by means of vector shape files

Aliya Aktymbayeva: Collection of primary materials in the field and their analysis in Mangistau oblast, districts: Kalamkas and Karazhanbas. Analysis of data and construction of schemes for the transformation of vegetation:

- $\quad$ Signs of oil and gas production (for fragment of Fig. 2)

- Scheme of outlining contours of hydrocarbon deposits in zones of various degrees of anthropogenic transformation of vegetation

Iztayeva Aziza: Collection of primary materials in the field and their analysis in Mangistua oblast, districts: Zhanaozen, Zhetybai Map building in Corel Draw:

- Map of plant transformation causrd by human impact

- Fragment of map of anthropogenic vegetation

\section{Ethics}

This article is original and contains unpublished material. The corresponding author confirms that all of the other authors have read and approved the manuscript and no ethical issues involved.

\section{References}

Abalakov, A.D., 2010. Ecological geology: Training manual. 1st Edn., Publishing House of the Irkut. State, University Press, Irkutsk.

Alekseenko, V.A., 2000. Environmental Geochemistry. 1st Edn., Logos, Moscow.

Araujo, M.B. and M. Luoto, 2007. The importance of biotic interactions for modelling species distributions under climate change. Global Ecol. Biogeography, 16: 743-753.

DOI: $10.1111 /$ j.1466-8238.2007.00359.x 
Avessalamova, I.A., 1992. Environmental assessment of terrains. MGU, Moscow.

Bevers, M. and J. Hof, 1999. Spatially optimizing wildlife habitat edge effects in forest management linear and mixed-integer programs. Forest Sci., 45: 249-258.

Boumans, R. and R. Costanza, 2002. Modeling the dynamics of the integrated earth system and the value of global ecosystem services using the GUMBO model. Ecol. Econom., 41: 529-560.

DOI: 10.1016/S0921-8009(02)00098-8

Burakov, M.M. and L.M. Pavlichenko, 2001. Hydrogeoecological zoning in view of systemic analysis. Proceedings of the International ScientificPractical Conference, (SPC' 01), Almaty Shartarap, pp: 70-76.

Chepurnykh, N.V. and A.L. Novoselov, 1995. Planning and Forecasting of Natural Resources: Textbook. 1st Edn., Interpraks, pp: 288.

Costanza, R., L. Wainger, C. Folke and K.G. Mdler, 1993. Modeling complex ecological economic systems. Bioscience, 43: 545-555.

DOI: $10.2307 / 1311949$

Cousins, S.A.O., S. Lavorel and I. Davies, 2003. Modelling the effects of landscape pattern and grazing regimes on the persistence of plant species with high conservation value in grasslands in southeastern Sweden. Landscape Ecol., 18: 315-332. DOI: 10.1023/A:1024400913488

DNRECMR, 2014. Newsletter of the state of environment of Mangistau region. Department of Natural Resources and Environmental Control in the Mangistau Region, Aktau.

Ecology of oil extraction complex. (n.d.). http://geologinfo.ru/ekologicheskaya-geologiya/152ekologiya-neftedobyvayushchegokompleksa.

Gmoshinsky, V.G., 1977. Engineering Ecology. 1st Edn., Knowledge, Moscow.

Guidelines for preparation of reports on environmental assessment.

(n.d.). http://www.grida.no/soe/cookbook/.

Imanbaeva, A.A. and M.S. Sagyndykova, 2009. Monitoring of vegetation in oil and gas field Karajanbas. Bull. KazNU, 1: 71-75.

Jeffers, J., 1981. Introduction to Systemic Analysis: Application in Ecology. 1st Edn., Mir., pp: 213.

Mangistau regional government. (n.d.). http://mangystau.gov.kz/ru/region/info/

Medeu, A.R., 2011. Atlas of Mangistau region. Almaty.

Milkov, F.N., 1990. General Land Science: Textbook Manual for Spec. Universities. 1st Edn., Higher Education, Moscow.

Moskovchenko, D.V., 1998. Oil and Gas Production and Environment. 1st Edn., Nauka, pp: 112.
Mukhina, L.I., 1973. Principles and Methods of Technology Assessment of Natural Systems. 1st Edn., Nauka, pp: 94.

Pavlichenko, L., A. Yespolayeva and A. Iztayeva, 2016. The impact of oil pollution on the formation of vegetation of Mangistau region. Pavlicenco, J.I.M., A.P. Espolaeva and A. Iztaeva (Republic of Kazakhstan) Effect of oil pollution on the formation of vegetation Mangistau region//"International scientific review of the problems and prospects of modern science and education." International Scientific Review of the Problems and Prospects of Modern Science and Education//International Scientific Review № 3 (13)/XI International Science Conference (New York. USA, 7- 8 March, 2016), pp: 25-32.

Pavlichenko, L.M. and A.S. Nysanbayeva, 2001. Evaluation of recreational influence of climatic factors of Caspian area in Kazakhstan. Proceedings of the International Scientific-Practical Conference, Jan. 22-23, Modern Problems of Geoecology and Sozology, Almaty, pp: 357-363.

Pavlichenko, L.M. and E.A. Kurbatova, 2006. A comprehensive assessment of the environmental impact of various technologies of uranium mining on the basis of objective function.//Geography of Kazakhstan: Contents, Problems and Prospects. Proceedings of the International ScientificPractical Conference, (SPC' 06), Almaty, pp: 174-176.

Pavlichenko, L.M., 2008. Comprehensive assessment of interaction between surface and groundwater by multivariate statistical models and objective function (based on example of Sokolovsky underground mine)//Water: Water resources, quality monitoring, water use and protection. Proceedings of the International Scientific-Practical Conference, (SPC' 08), pp: 117-120.

Pavlichenko, L.M., D.I. Baymuratova and A.R. Espolaeva, 2015. Assessing the impact of oil and gas extraction complex of Mangistau region on anthropogenic modification of relief. Oil Gas, 4: 133-14.

Pavlichenko, L.M., E.A. Talanov, J.D. Dostai and A.V. Chigarkin, 2010. Ranging of regions of Kazakhstan by intensity of desertification by constructing objective function. Hydrometeorol. Ecol., 2: 201-212.

Pavlichenko, L.M., R.U. Mukasheva, S.M. Bayandinova and V.S. Krylova, 2012. Environmental impact assessment of the eastern Kazakhstan based on standardized efficiency function according to cartographic documents. World Applied Sci. J., 19: 302-308.

DOI: 10.5829/idosi.wasj.2012.19.03.2766 
Pavlichenko, L.M., Z.S. Urikbaeva and A.V. Chigarkin, 2002. Expert assessment of human impact on natural environment of Kyzylorda region with the help of objective function. Bull. KNU, 1: 70-74.

Pentl, R., 1979. Methods of Systemic Analysis of Environment. 1st Edn., Mir., pp: 215.
Peregudov, F.I. and F.P. Tarasenko, 1989. Introduction to Systemic Analysis. 1st Edn., Nauka, pp: 477.

Sokolov, V.E., 1992. Ecoinformatics: Theory, Practice, Methods and Systems. 1st Edn., SPb., Gidrometeoizdat, pp: 495. 